\title{
Sensory profile and acceptability for pitanga (Eugenia uniflora L.) nectar with different sweeteners
}

\author{
Mírian Luisa Faria Freitas ${ }^{1}$, Mariana Borges de Lima Dutra ${ }^{2}$ and \\ Helena Maria André Bolini ${ }^{3}$
}

\begin{abstract}
The objective of this study was to evaluate the sensory properties and acceptability of pitanga nectar samples prepared with sucrose and different sweeteners (sucralose, aspartame, stevia with 40\% rebaudioside A, stevia with $95 \%$ rebaudioside A, neotame, and a 2:1 cyclamate/saccharin blend). A total of 13 assessors participated in a quantitative descriptive analysis and evaluated the samples in relation to the descriptor terms. The acceptability test was carried out by 120 fruit juice consumers. The results of the quantitative descriptive analysis of pitanga nectar showed that samples prepared with sucralose, aspartame, and the 2:1 cyclamate/saccharin blend had sensory profiles similar to that of the sample prepared with sucrose. Consumers' most accepted samples were prepared with sucrose, sucralose, aspartame, and neotame. The sweeteners that have the greatest potential to replace sucrose in pitanga nectar are sucralose and aspartame.
\end{abstract}

\section{Keywords}

Tropical fruit, low-calorie beverage, quantitative descriptive analysis, affective testing, external preference mapping

Date received: 19 March 2015; accepted: 24 August 2015

\section{INTRODUCTION}

Pitanga (Eugenia uniflora L.), also known as "surinam cherry" or "Brazilian cherry", is the fruit of a perennial tree of the Myrtaceae family, native to South America. Despite its tropical origin, its cultivation is already widespread in many countries, and it can be found in some Asian countries, United States and Caribbean (Garmus et al., 2014). Pitanga is a fruit with excellent conditions for industrialization due to its high pulp content, pleasant aroma, and exotic flavor (Karwowski et al., 2013). Moreover, it is rich in calcium, phosphorus, flavonoids, carotenoids, vitamin $\mathrm{C}$, and potassium (Silva, 2006; Soares et al., 2004).

Refined sugars, syrups or artificial sweeteners are used to sweeten fruit juice and nectar. However, it is important to consider that the overall increase in

Food Science and Technology International 22(8) 720-731

(C) The Author(s) 2016 Reprints and permissions:

sagepub.co.uk/journalsPermissions.nav

DOI: $10.1177 / 1082013215607077$

fst.sagepub.com

๑SAGE obesity has been partly attributed to an overall increase in consumption of refined sugars, such as sucrose and fructose. Artificial sweeteners can provide sweetness without contributing to the food's caloric value, due to their intense levels of sweetness. It is also important to consider the increase in diabetes that places restrictions on the consumption of sugars. Thus, global trends indicate that the consumption of artificial sweeteners is increasing, and foods produced with these sweeteners are constantly being added to the supermarket shelves (Mahar and Duizer, 2007).

\footnotetext{
${ }^{1}$ Department of Food Engineering and Technology, State University of São Paulo, São José do Rio Preto, São Paulo, Brazil ${ }^{2}$ National Institute of Education, Science and Technology of the South of Minas Gerais State, Inconfidentes, Minas Gerais, Brazil ${ }^{3}$ Department of Food and Nutrition, University of Campinas, Campinas, São Paulo, Brazil
}

Corresponding author:

Mírian Luisa Faria Freitas, Department of Food Engineering and Technology, UNESP_State University of São Paulo, 2265 Cristóvão Colombo Street, Jardim Nazareth, 15.054-000 São José do Rio Preto, São Paulo, Brazil.

Email: mirianlfreitas@yahoo.com.br 
Sucralose is a high-intensity sweetener derived from sucrose. Its pleasant sensory profile with no residual flavor, high water solubility, and physicochemical stability allow it to be used in acidic foods and thermally processed products without loss of sweetness (Basu et al., 2013). Humans do not metabolize it; furthermore, sucralose is considered an option for improving quality of life for the diabetic population (Viberg and Fredriksson, 2011).

Aspartame has excellent solubility in water and alcohol, but it is insoluble in fats and oils (Nabors, 2002). Under certain moisture conditions, temperature and $\mathrm{pH}$, hydrolysis can occur resulting in loss of sweetness. Despite suffering hydrolysis with overheating, aspartame is compatible with the thermal treatment used in juices and dairy products (Wells, 1989). Following ingestion, aspartame is metabolized to phenylalanine, aspartic acid, and methanol (Ranney et al., 1976), and its use should be controlled by phenylketonurics.

Stevia is a natural sweetener known for its high sweet diterpene glycosides content (about $4-20 \%$ in dried leaves) responsible for the sweet taste (Ghanta et al., 2007). Stevioside is described as a glycoside composed of three glucose molecules bonded to an aglycone. During the 1970s, other compounds were isolated, including rebaudioside with sweetening power higher than stevioside (Barriocanal et al., 2008). In this way, studies allowed the development of new extracts with higher proportions of the rebaudioside A (between $40 \%$ and 97\%), which provides a better product flavor than the other constituents (Hough, 1996).

Neotame is a strong sweetener, with sweetness for humans ranging from 7000 to 13,000 times greater than sucrose, and can be used to sweeten foods and beverages as well as to modify and enhance the flavor of foods (Flamm et al., 2003). The profile of the sweetness from neotame is similar to that of sucrose. As happens with other sweeteners, the strength of the sweetness of neotame depends on its concentration and the food or beverage to which it will be added (Sedivá et al., 2006).

Cyclamate can be heated to temperatures higher than $500^{\circ} \mathrm{C}$ without decomposition; it is easily soluble in water, and it may be used as a non-caloric sweetener in many foods including soft drinks, desserts, and processed vegetables (Salminen and Hallikainen, 2002). Its performance is interesting in products derived from fruit due to its ability to enhance fruity flavors and to mask the acidity from certain citric fruits (Nabors, 2002).

In aqueous solutions, saccharin has a little residual bitter taste and residual metallic flavor that limits its use (Newsome, 1993). However, these characteristics can be minimized by the combined use with other sweeteners due to a synergistic capability of masking the residual flavor effect (Hough, 1996; Salminen and Hallikainen, 2002). The main advantage of the combined use of saccharin and cyclamate is to increase the sweetening power of cyclamate, as cyclamate masks the residual flavor of saccharin (Higginbotham, 1983; Nabors, 2002).

According to Amerine et al. (1965), the flavor of a fruit and its juices and nectars is the result of the sum of perceptions resulting from stimulation of the sense ends that are grouped together at the entrance of the alimentary and respiratory tracts, determining the balance of these characteristics in each product. The only way to measure these sensations is by sensory analysis, since the human response cannot be reproduced by any equipment.

The most widely acceptable scientific strategy for sensory quality evaluation takes into account the relationship between two types of data: tests with consumers and trained analytical assessors. The relationship between these makes it possible to determine sensory profiles which are best adapted to the concept of the product quality in the target market, enabling companies to establish control activities, improve quality and develop new products (Elortondo et al., 2007).

According to Resano et al. (2010), matching consumers' needs is a priority in market-oriented companies, and in this sense, consumers' acceptability of a food product is considered to be a trigger for subsequent purchases and, as such, a contributing factor to the company's ultimate success. Trained panelists, on the other hand, assess sensory profile according to the conformity of an array of descriptors to predetermined standards and consequently provide valuable information to the food industry about the characteristics of their products. The combination of consumers' scores on acceptability and trained panelists' assessments on an array of sensory attributes enabled an investigation of the degree of convergence between both groups of tasters in terms of pleasantness intensity and identification of the sensory drivers of consumers' acceptability and their coherence with those of trained panelists' sensory profile assessment.

Two types of preference mapping can be distinguished: external and internal (Carrol, 1972). The former relates consumers' acceptability to sensory, physical and/or chemical data, whereas the latter only uses consumers' acceptability scores to achieve a multidimensional representation of the products (Greenhoff and Macfie, 1994). In other words, the external mapping aims at explaining the sensorial (and/or instrumental) reasons of consumers' preferences (Resano et al., 2010).

In this context, the study of pitanga nectar prepared with sucrose and high-intensity sweeteners is relevant, 
because the fruit is rich in nutrients and provides conditions for industrialization, and the Brazilian production has great market potential. Using sweeteners instead of sucrose meets the needs of consumers who cannot consume sugars due to metabolic disorders, and of those seeking less caloric food. So, the objective of this study was to determine the sensory profile, consumer acceptability, and their interaction regarding the pitanga nectar prepared with different sweeteners, by sensory methods.

\section{MATERIALS AND METHODS}

\section{Materials}

The pitanga nectar samples were prepared with unsweetened frozen pulp (Ricaeli ${ }^{\mathrm{TM}}$, Cabreúva, Brazil), drinking water, and sweeteners. The sweeteners were: sucrose (União ${ }^{\mathrm{TM}}$, São Paulo, Brazil), sucralose (Tovani-Benzaquem $^{\mathrm{TM}}$, São Paulo, Brazil), aspartame (All Chemistry do Brasil ${ }^{\mathrm{TM}}$, São Paulo, Brazil), stevia $40 \%$ rebaudioside A (Clariant $^{\mathrm{TM}}$, Suzano, Brasil), stevia $95 \%$ rebaudioside A (Tovani-Benzaquem ${ }^{\mathrm{TM}}$, São Paulo, Brazil), neotame (Sweetmix ${ }^{\mathrm{TM}}$, Sorocaba, Brazil), and a blend (2:1) of cyclamate (Sweetmix ${ }^{\mathrm{TM}}$, Sorocaba, Brazil)/saccharin (Pharma Nostra ${ }^{\mathrm{TM}}$, Rio de Janeiro, Brazil).

\section{Methods}

Samples. Seven pitanga nectar samples were prepared in the Laboratory of Sensory Analysis in the Department of Food and Nutrition at the University of Campinas the day before each test.

The ideal pulp dilution (25\% pulp) and ideal sweetness with sucrose $(10 \%$ sucrose $)$ were previously determined by consumers using a just-about-right scale. The equi-sweet concentrations of sweeteners were also previously determined by assessors, using the magnitude estimation model. Sweetener concentrations to replace sucrose were $0.016 \%$ sucralose, $0.0541 \%$ aspartame, $0.1 \%$ stevia $40 \%$ rebaudioside A, $0.1 \%$ stevia $95 \%$ rebaudioside A, $0.0017 \%$ neotame and $0.036 \% \quad 2: 1$ cyclamate/saccharin blend. In addition, microbiological analyses were carried out on the pitanga pulp in order to avoid any risk to the healthy tasters (Freitas et al., 2014).

Quantitative descriptive analysis. The samples were presented using a balanced complete block design (Macfie, 1989) in a monadic sequential way, $30 \mathrm{~mL}$ at $10^{\circ} \mathrm{C}$ in disposable plastic glasses, coded with threedigit numbers. The tasters used an unstructured $9-\mathrm{cm}$ scale ranging from "weak" to "strong" or "none" to "strong", depending on the descriptor term, in the Fizz $^{\mathrm{TM}}$ software (version 2.47, Biosystemes,
Coutemon, France) in individual booths in the laboratory at $22^{\circ} \mathrm{C}$. The tasters had available water to drink in order to clean their palate.

Several people were submitted to Walds sequential analysis, using triangle tests (Amerine et al., 1965) to select those with high discrimination ability. For these tests, two pitanga nectar samples were used, sweetened with $3.5 \%$ and $5 \%$ sucrose. These samples presented a significant difference at $0.1 \%$ significance level in a paired comparison test.

Fourteen judges were selected using the following parameters: $\rho_{0}=0.33$ (maximum acceptable inability), $\rho_{1}=0.66$ (minimum acceptable ability), $\alpha=0.05$ (probability of accepting a candidate without sensory acuity) and $\beta=0.05$ (probability of rejecting a candidate with sensory acuity). To be selected, the tasters had to choose the correct answer in at least seven out of nine tests. When they did not reach this result, they could continue the tests and had to choose the correct answer in at least eight of 12 tests (Augusto et al., 2005; Moraes and Bolini, 2010).

The selected tasters determined the descriptor terms for the pitanga nectar samples using Kelly's Repertory Grid Method (Moskowitz, 1988). In consensus, the tasters defined the terms that best described the samples and elaborated references to calibrate the scales (Meilgaard et al., 2007), which can be seen in Table 1 . References for each attribute were prepared for the tasters' training. The tasters were trained in three 1$\mathrm{h}$ training sessions, forming the sensory memory for each attribute.

After training, tasters were submitted to definitive team selection for quantitative descriptive analysis. They evaluated three pitanga nectar samples in three replicates and were selected based on each taster's discrimination ability, reproducibility of judgments, and agreement with the other members of the group, verified by a two-factor analysis of variance (ANOVA; sample and repetition) for each taster in relation to each attribute (Damásio and Costell, 1991). Tasters with good discrimination ability $(p \leq 0.50)$, reproducibility of judgments $(p>0.05)$, and group consensus were selected to compose the panel.

A total of 13 assessors were selected to compose the definitive team and evaluated the seven samples in three replicates. One man and 12 women composed the team. They were between 20 and 30 years old.

Affective testing. The affective testing was conducted with 120 fruit juice consumers, men and women between 18 and 60 years old, using an unstructured 9$\mathrm{cm}$ hedonic scale ranging from "extremely dislike" to "extremely like" for appearance, odor, flavor, texture, and overall impression. The samples were presented in $30 \mathrm{~mL}$ at $10^{\circ} \mathrm{C}$ in disposable plastic glasses, coded with 
Freitas et al.

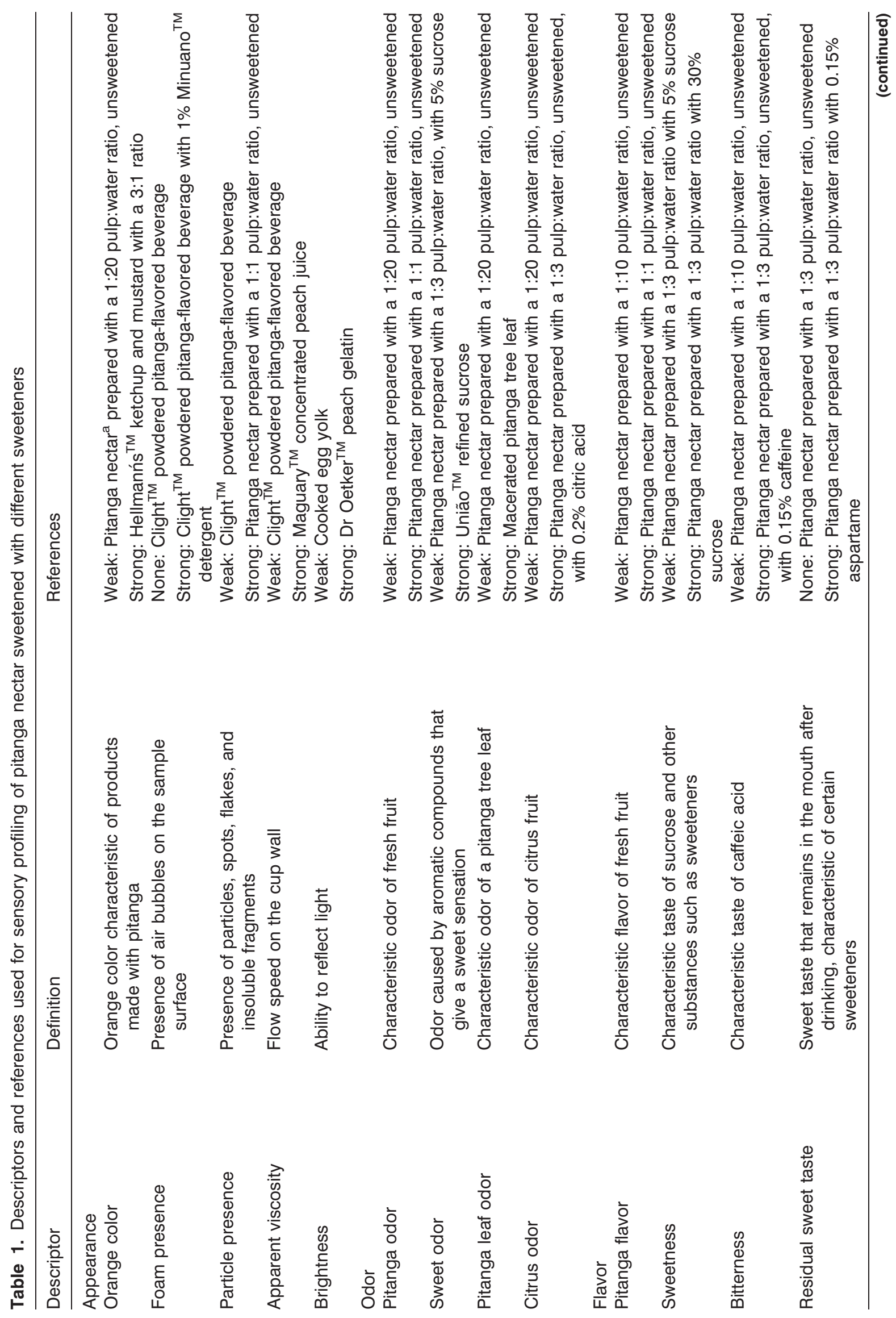




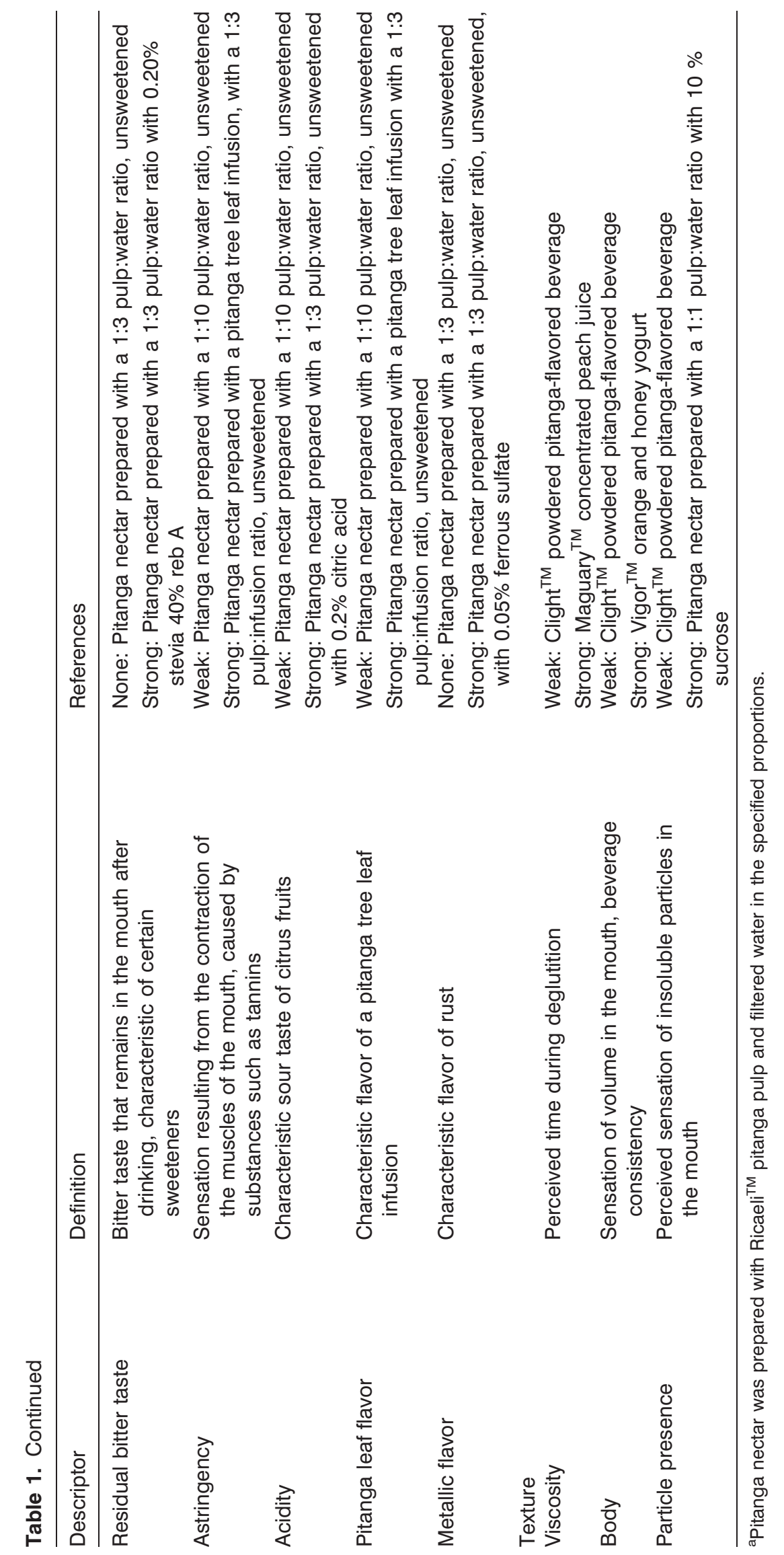


three-digit numbers in individual booths in the laboratory at $22^{\circ} \mathrm{C}$. They were presented in one session using a balanced complete block design in a monadic sequential way, and the consumers received water between the samples in order to clean their palate (Hough et al., 2006; Stone et al., 2012).

Statistical analysis. Data obtained from the descriptive quantitative analysis were evaluated by two-factor with interaction analysis of variance (ANOVA) and the Tukey's test using the SAS software (version 9.1.2, SAS Institute, Cary, NC). These data were also analyzed by principal component analysis with covariation matrix using the software XLSTAT (Addinsoft, Paris, France). The data from the affective testing were evaluated by ANOVA and the Tukeýs test using the SAS software.

Descriptive information obtained from the trained panel was related to the consumer preference data using partial least squares regression (PLS) (Tenenhaus et al., 2005). An external preference mapping multivariate statistical analysis allowed the generation of a multidimensional sensory affective space formed by the consumers, attributes, and samples. These analyses were carried out using the software XLSTAT.

This research project was submitted to and approved by the Research Ethics Committee from the University of Campinas, CEP n ${ }^{\circ}$ 1264/2011. Moreover, a Term of Consent containing information about the research was prepared and presented to the tasters.

\section{RESULTS AND DISCUSSION}

\section{Quantitative descriptive analysis}

The attribute means for each sample are given in Table 2. Regarding appearance, the pitanga nectar samples did not significantly differ $(p>0.05)$ in orange color, foam presence, apparent viscosity, and brightness, showing that the sweeteners did not influence these attributes. The samples prepared with sucrose, sucralose,

Table 2. Attribute means for each pitanga nectar sample prepared with different sweeteners in quantitative descriptive analysis

\begin{tabular}{|c|c|c|c|c|c|c|c|c|}
\hline Attributes & Sucrose & Sucralose & Aspartame & Stevia $40 \%$ & Stevia 95\% & Neotame & $\begin{array}{l}2: 1 \text { cyclamate/ } \\
\text { saccharin }\end{array}$ & $p$ value \\
\hline \multicolumn{9}{|l|}{ Appearance } \\
\hline Orange color & $6.23^{a}$ & $6.66^{\mathrm{a}}$ & $6.66^{\mathrm{a}}$ & $6.41^{\mathrm{a}}$ & $6.51^{\mathrm{a}}$ & $6.38^{a}$ & $6.42^{a}$ & 0.4113 \\
\hline Foam presence & $0.18^{a}$ & $0.22^{\mathrm{a}}$ & $0.17^{\mathrm{a}}$ & $0.16^{\mathrm{a}}$ & $0.13^{\mathrm{a}}$ & $0.20^{\mathrm{a}}$ & $0.18^{\mathrm{a}}$ & 0.4239 \\
\hline Particle presence & $5.13^{\mathrm{a}}$ & $5.18^{\mathrm{a}}$ & $5.28^{\mathrm{a}}$ & $4.79^{b}$ & $4.45^{\mathrm{b}}$ & $4.99^{\mathrm{b}}$ & $4.78^{\mathrm{b}}$ & 0.0029 \\
\hline Apparent viscosity & $4.16^{\mathrm{a}}$ & $4.49^{\mathrm{a}}$ & $4.29^{\mathrm{a}}$ & $4.11^{\mathrm{a}}$ & $4.02^{\mathrm{a}}$ & $4.39^{\mathrm{a}}$ & $4.25^{\mathrm{a}}$ & 0.3913 \\
\hline Brightness & $6.40^{\mathrm{a}}$ & $6.65^{\mathrm{a}}$ & $6.08^{\mathrm{a}}$ & $6.35^{\mathrm{a}}$ & $6.49^{\mathrm{a}}$ & $6.32^{\mathrm{a}}$ & $6.66^{\mathrm{a}}$ & 0.2215 \\
\hline \multicolumn{9}{|l|}{ Odor } \\
\hline Pitanga odor & $6.34^{\mathrm{a}}$ & $6.56^{\mathrm{a}}$ & $6.41^{\mathrm{a}}$ & $6.45^{\mathrm{a}}$ & $6.37^{\mathrm{a}}$ & $6.52^{\mathrm{a}}$ & $6.69^{a}$ & 0.1897 \\
\hline Sweet odor & $3.52^{\mathrm{a}}$ & $3.62^{\mathrm{a}}$ & $3.91^{\mathrm{a}}$ & $3.88^{\mathrm{a}}$ & $3.26^{\mathrm{a}}$ & $4.00^{\mathrm{a}}$ & $3.64^{\mathrm{a}}$ & 0.0629 \\
\hline Pitanga leaf odor & $4.09^{\mathrm{a}}$ & $4.13^{\mathrm{a}}$ & $4.16^{\mathrm{a}}$ & $3.91^{\mathrm{a}}$ & $4.17^{\mathrm{a}}$ & $4.06^{\mathrm{a}}$ & $4.17^{\mathrm{a}}$ & 0.5708 \\
\hline Citrus odor & $3.42^{\mathrm{a}}$ & $3.36^{\mathrm{a}}$ & $3.54^{\mathrm{a}}$ & $3.10^{\mathrm{a}}$ & $2.95^{\mathrm{a}}$ & $3.01^{\mathrm{a}}$ & $3.12^{\mathrm{a}}$ & 0.1369 \\
\hline \multicolumn{9}{|l|}{ Flavor } \\
\hline Pitanga flavor & $6.12^{\mathrm{a}}$ & $6.55^{\mathrm{a}}$ & $6.55^{\mathrm{a}}$ & $6.46^{\mathrm{a}}$ & $6.49^{\mathrm{a}}$ & $6.34^{\mathrm{a}}$ & $6.46^{\mathrm{a}}$ & 0.2715 \\
\hline Sweetness & $5.13^{\mathrm{c}}$ & $5.47^{\mathrm{b}, \mathrm{c}}$ & $5.65^{\mathrm{b}, \mathrm{c}}$ & $5.84^{\mathrm{b}, \mathrm{c}}$ & $6.27^{\mathrm{a}, \mathrm{b}}$ & $6.77^{\mathrm{a}}$ & $5.08^{\mathrm{c}}$ & $<0.0001$ \\
\hline Bitterness & $1.86^{\mathrm{d}}$ & $1.91^{d}$ & $2.64^{\mathrm{c}, \mathrm{d}}$ & $5.26^{a}$ & $4.40^{\mathrm{a}, \mathrm{b}}$ & $2.43^{\mathrm{c}, \mathrm{d}}$ & $3.43^{b, c}$ & $<0.0001$ \\
\hline Residual sweet taste & $1.36^{\mathrm{e}}$ & $3.14^{\mathrm{c}}$ & $2.87^{c, d}$ & $4.57^{\mathrm{b}}$ & $5.13^{a, b}$ & $5.99^{a}$ & $1.99^{\mathrm{d}, \mathrm{e}}$ & $<0.0001$ \\
\hline Residual bitter taste & $1.49^{d}$ & $1.67^{d}$ & $2.57^{\mathrm{c}, \mathrm{d}}$ & $5.26^{\mathrm{a}}$ & $4.36^{\mathrm{a}, \mathrm{b}}$ & $2.64^{\mathrm{c}, \mathrm{d}}$ & $3.26^{b, c}$ & $<0.0001$ \\
\hline Astringency & $3.86^{b}$ & $3.97^{\mathrm{a}, \mathrm{b}}$ & $3.92^{\mathrm{a}, \mathrm{b}}$ & $4.45^{\mathrm{a}}$ & $4.24^{a, b}$ & $3.91^{\mathrm{a}, \mathrm{b}}$ & $4.25^{a, b}$ & 0.0129 \\
\hline Acidity & $3.12^{\mathrm{a}}$ & $3.23^{\mathrm{a}}$ & $3.04^{\mathrm{a}}$ & $3.46^{\mathrm{a}}$ & $3.51^{\mathrm{a}}$ & $3.28^{a}$ & $3.38^{a}$ & 0.1284 \\
\hline Pitanga leaf flavor & $4.18^{\mathrm{a}, \mathrm{b}}$ & $4.36^{\mathrm{a}, \mathrm{b}}$ & $4.17^{\mathrm{a}, \mathrm{b}}$ & $4.47^{\mathrm{a}}$ & $4.23^{\mathrm{a}, \mathrm{b}}$ & $4.01^{\mathrm{b}}$ & $4.57^{\mathrm{a}}$ & 0.0024 \\
\hline Metallic flavor & $1.30^{\mathrm{b}, \mathrm{c}}$ & $1.22^{\mathrm{b}, \mathrm{c}}$ & $1.20^{\mathrm{C}}$ & $2.05^{\mathrm{a}}$ & $1.52^{\mathrm{b}}$ & $1.20^{\mathrm{c}}$ & $1.45^{\mathrm{b}, \mathrm{c}}$ & $<0.0001$ \\
\hline \multicolumn{9}{|l|}{ Texture } \\
\hline Viscosity & $3.80^{\mathrm{a}}$ & $3.81^{\mathrm{a}}$ & $4.04^{\mathrm{a}}$ & $3.82^{\mathrm{a}}$ & $4.05^{\mathrm{a}}$ & $3.99^{\mathrm{a}}$ & $3.82^{\mathrm{a}}$ & 0.2324 \\
\hline Body & $3.24^{\mathrm{a}}$ & $3.39^{\mathrm{a}}$ & $3.68^{\mathrm{a}}$ & $3.44^{\mathrm{a}}$ & $3.59^{\mathrm{a}}$ & $3.49^{\mathrm{a}}$ & $3.53^{\mathrm{a}}$ & 0.2019 \\
\hline Particle presence & $3.32^{\mathrm{a}}$ & $3.23^{\mathrm{a}}$ & $3.50^{\mathrm{a}}$ & $3.33^{\mathrm{a}}$ & $3.34^{\mathrm{a}}$ & $3.41^{\mathrm{a}}$ & $3.32^{\mathrm{a}}$ & 0.8983 \\
\hline
\end{tabular}

Means in a row followed by different letters are significantly different $(p \leq 0.05)$, with ${ }^{\text {a }}$ representing the higher value. 
and aspartame had the highest averages for particle presence.

Differing from the results for pitanga nectar, in a study conducted by Cardoso and Bolini (2008) with peach nectar prepared with different sweeteners, the sample prepared with sucrose had the highest average for apparent viscosity, significantly differing $(p \leq 0.05)$ from the other samples.

The pitanga nectar samples did not significantly differ $(p>0.05)$ in the odor attributes, that is, pitanga odor, sweet odor, pitanga leaf odor, and citrus odor. This suggests that the sweeteners used did not affect the odor attributes.

Regarding flavor attributes, the pitanga nectar samples did not significantly differ $(p>0.05)$ only for the attributes such as pitanga flavor and acidity, suggesting that the sweeteners did not significantly influence these natural pitanga nectar attributes.

Among the pitanga nectar samples, those prepared with neotame and stevia $95 \%$ rebaudioside A had the highest averages $(p<0.05)$ for sweetness and did not significantly differ $(p>0.05)$ between themselves. However, sweetness of samples with stevia $95 \%$ did not significantly differ $(p>0.05)$ from those with sucralose, aspartame and stevia $40 \%$. On the other hand, those prepared with the 2:1 cyclamate/saccharin blend and sucrose had the lowest averages, and they did not significantly differ $(p>0.05)$ from the samples with sucralose, aspatame, and stevia $40 \%$.

The pitanga nectar samples prepared with stevia $40 \%$ rebaudioside A and stevia $95 \%$ rebaudioside A presented the highest averages for bitterness and did not significantly differ $(p>0.05)$ between themselves, revealing the bitter taste present in these sweeteners. However, the sample with stevia $95 \%$ rebaudioside did not significantly differ $(p>0.05)$ from that with 2:1 cyclamate/saccharin blend that significantly differed $(p<0.05)$ from that with stevia $40 \%$ rebaudioside. This might show a tendency of lower bitterness for stevia $95 \%$ rebaudioside compared with $40 \%$ rebaudioside. Pitanga nectar samples prepared with sucrose and sucralose showed the lowest averages, and they did not significantly differ $(p>0.05)$ from those prepared with aspartame and neotame. These values are not null, suggesting that the pitanga nectar had the bitter taste of natural fruit and that sweeteners increased this attribute.

As a comparison, regarding the peach nectar, the sample that presented the highest average for bitterness was also that prepared with stevia (Cardoso and Bolini, 2008). Similar results were found by Umbelino and Bolini (2005) while studying mango juice.

Similar to the sweetness attribute, for the residual sweet taste attribute, the pitanga nectar samples prepared with neotame and stevia $95 \%$ rebaudioside A presented the highest averages and did not significantly differ $(p>0.05)$ between themselves; however, the sample with stevia $95 \%$ rebaudioside did not significantly differ $(p>0.05)$ from that with stevia $40 \%$ rebaudioside. The samples prepared with the 2:1 cyclamate/saccharin blend and sucrose had the lowest averages and did not significantly differ $(p>0.05)$ between themselves; however, the sample with $2: 1$ cyclamate/ saccharin blend did not significantly differ $(p>0.05)$ from that with aspartame.

Umbelino and Bolini (2005), while studying mango juice, showed that among the samples, the one that presented the highest average for residual sweet taste was prepared with stevia. Considering that these authors did not use neotame in their samples, the results correspond to those found in the present study.

Regarding residual bitter taste, the pitanga nectar samples prepared with stevia $40 \%$ rebaudioside A and stevia $95 \%$ rebaudioside $\mathrm{A}$ had the highest averages and did not significantly differ $(p>0.05)$ between themselves. Similarly, for the bitterness, the sample with stevia $95 \%$ rebaudioside did not significantly differ $(p>0.05)$ from that with 2:1 cyclamate/saccharin blend that significantly differed $(p<0.05)$ from that with stevia $40 \%$ rebaudioside. Samples prepared with sucrose, sucralose, aspartame, and neotame had the lowest averages and did not significantly differ ( $p>0.05)$ among them, showing that these sweeteners in pitanga nectar have little residual bitter taste that remains in the mouth after swallowing, and it might was provided by little bitter taste naturally presented in pitanga nectar (Table 2).

Similar results were found by Cardoso and Bolini (2008) while studying peach nectar. Umbelino and Bolini (2005), while studying mango juice, also found a higher average for residual bitter taste in the sample prepared with stevia.

It is interesting that, despite the large difference in rebaudioside in the two sweeteners from stevia used to prepare the pitanga nectar, these samples did not differ in the attributes of sweetness, residual sweet taste, bitterness, and residual bitter taste, as expected, once the increase in rebaudioside content could increase the sweetness and decrease the bitterness. This suggests that the characteristic bitter taste of stevia did not cease to be evident due to the higher percentage of rebaudioside, in pitanga nectar. But, a tendency of lower bitterness and residual bitter taste for stevia $95 \%$ rebaudioside was noted compared with stevia $40 \%$ rebaudioside.

The different sweeteners did not affect the texture attributes significantly, that is, the pitanga nectar samples did not significantly differ $(p>0.05)$ in the viscosity, body, and particle presence.

The results obtained in the quantitative descriptive analysis were submitted to principal component 
analysis (Figure 1). The principal component analysis was presented with the principal components 1 and 2 including the attributes that are significantly different $(p<0.05)$ among the samples. From this graph, it is possible to see which samples were close to each other, and which attributes more likely characterized them.

According to Figure 1, the pitanga nectar prepared with sucrose, sucralose, and aspartame are close, suggesting that they had similar sensory profiles. Samples prepared with stevia $40 \%$ rebaudioside A and stevia $95 \%$ rebaudioside $\mathrm{A}$ are close and are characterized by the attributes such as bitterness and residual bitter taste. Furthermore, it was observed that the samples prepared with neotame and stevia $95 \%$ rebaudioside A were characterized by the attributes such as sweetness and residual sweet taste.

\section{Affective testing}

The attribute means given by consumers are presented in Table 3. These results show in which attributes the samples presented a significant difference $(p \leq 0.05)$ and which had the highest averages, showing higher acceptance.
Regarding their appearance, the samples did not significantly differ $(p>0.05)$ among themselves. For acceptance in relation to odor, the samples prepared with the 2:1 cyclamate/saccharin blend, sucrose, sucralose, aspartame, stevia 95\% rebaudioside, and neotame had the highest average and did not significantly differ $(p>0.05)$ between them. However, the samples with sucrose, sucralose, aspartame, stevia $95 \%$ rebaudioside, and neotame did not significantly differ $(p>0.05)$ from the sample with stevia $40 \%$ rebaudioside.

Regarding the attribute flavor, the samples prepared with sucrose, sucralose, aspartame, and neotame showed the highest average with no difference between them $(p>0.05)$. On the other hand, the samples prepared with stevia $40 \%$ rebaudioside A and with stevia 95\% rebaudioside $\mathrm{A}$ had the lowest averages, showing consumers' rejection for these samples, regarding flavor.

As far as the texture is concerned, that is, viscosity and body, the sample prepared with sucrose, sucralose, aspartame, stevia 95\% rebaudioside, neotame and 2:1 cyclamate/saccharin blend obtained the highest average with no difference between them $(p \leq 0.05)$. But, the samples with sucralose, aspartame, stevia $95 \%$ rebaudioside, neotame, and 2:1 cyclamate/saccharin blend

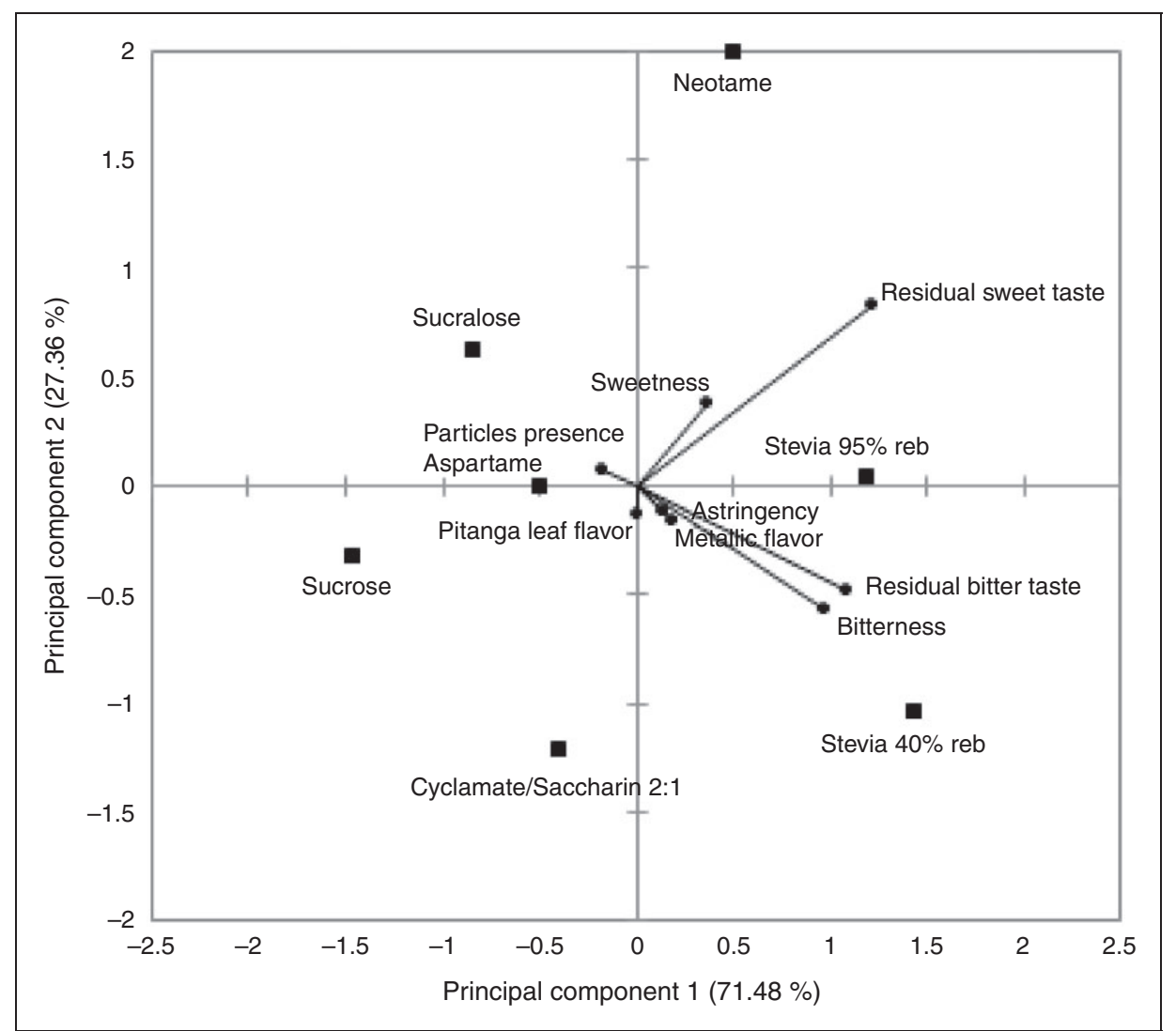

Figure 1. Principal component analysis graphic for pitanga nectar prepared with different sweeteners, PC1 $\times$ PC2 (98.85\%). 
did not significantly differ $(p>0.05)$ from the sample with stevia $40 \%$ rebaudioside. Finally, regarding overall impression, sucrose, sucralose, aspartame, and neotame samples had the highest acceptance, with no difference between them $(p>0.05)$; however, sucralose, aspartame, and neotame samples did not significantly differ $(p>0.05)$ from 2:1 cyclamate/saccharin blend sample.

The external preference mapping was constructed using the data from consumer acceptance for overall impression and the averages of attribute descriptors obtained in the trained assessors' quantitative descriptive analysis. This external preference mapping is shown in Figure 2. Pitanga nectar samples were more likely characterized by the descriptor terms that were close to them, and the consumers were near the samples of their preference.

The external preference mapping obtained by principal components 1 and 2 explained $45.82 \%$ of the variation between the samples. This value, which was relatively low, can be explained by the consumers' preference being divided among more than one sample. Indeed, it is possible to see in Table 3 that, in general, consumers did not strongly differentiate samples' overall impression acceptances (no significant difference, $p>0.05$, between the samples prepared with sucrose, sucralose, aspartame, and neotame). However, the seven samples are spread out in Figure 2. Therefore, the "general no difference" indicated in Table 3 can be seen in Figure 2 since many consumers are close to the beginnings of principal components 1 and 2, suggesting that they do not contribute to samples' differentiation.

In the external preference mapping (Figure 2), the consumers were located near the sample of their choice, those prepared with sucrose, neotame, sucralose, and aspartame. In addition, these samples were characterized by attributes such as pitanga odor, orange color, and sweet odor. In fact, these samples had the highest averages for overall impression in the Tukey's test (Table 3). The samples prepared with sucrose, sucralose, and aspartame presented similar sensory profiles, and the samples prepared with neotame presented a different sensory profile from them and it was characterized by the attributes of residual sweet taste and sweetness. Thus, it is suggested that different groups of consumers might prefer different samples due to their different sensory profiles.

The samples prepared with stevia $40 \%$ rebaudioside A, stevia $95 \%$ rebaudioside A and the 2:1 cyclamate/ saccharin blend presented results very far from the concentration of tasters, showing that they were rejected. These samples showed the lowest average according to the Tukey's test for overall impression (Table 3). The samples were prepared with stevia $40 \%$ rebaudioside and stevia $95 \%$ rebaudioside, and were characterized by attributes such as residual bitter taste, residual sweet taste, and metallic flavor.

To visualize which descriptor terms had positive or negative influence on the consumers' decision for overall impression in the acceptance analysis, a PLS regression was performed between the descriptor terms and the averages of overall impression of pitanga nectar samples. The standardized coefficients of the regression are shown in Figure 3. The confidence interval for this regression was $95 \%$.

The descriptor terms presented a confidence interval below zero, showing a significant negative influence on the score attributed to the overall impression in the acceptance test. These terms are bitterness, residual sweet taste, residual bitter taste, astringency, acidity, and metallic flavor.

These terms were attributed to the samples prepared with stevia $40 \%$ rebaudioside A or stevia $95 \%$ rebaudioside $\mathrm{A}$, in accordance with the external preference mapping (Figure 2). This explains the low average these samples obtained in the Tukey's test for the overall impression in the acceptance test (Table 3).

Voorpostel et al. (2014) reported that the purple color and grape flavor had a positive effect on the acceptance of six samples of grape nectar, each one sweetened with one different sweetener, and wine aroma, astringency, bitter taste, and bitter aftertaste adversely affected the sensory acceptance. In the evaluation of mango nectar,

Table 3. Attribute means for each pitanga nectar sample prepared with different sweeteners in affective testing

\begin{tabular}{|c|c|c|c|c|c|c|c|c|}
\hline Attributes & Sucrose & Sucralose & Aspartame & Stevia $40 \%$ & Stevia 95\% & Neotame & $\begin{array}{l}2: 1 \text { cyclamate/ } \\
\text { saccharin }\end{array}$ & DMS* \\
\hline Appearance & $5.09^{a}$ & $5.20^{a}$ & $5.07^{a}$ & $5.43^{a}$ & $5.41^{\mathrm{a}}$ & $5.19^{a}$ & $5.48^{a}$ & 0.48 \\
\hline Odor & $4.96^{a, b}$ & $4.96^{a, b}$ & $4.77^{\mathrm{a}, \mathrm{b}}$ & $4.69^{b}$ & $4.78^{a, b}$ & $4.89^{a, b}$ & $5.26^{\mathrm{a}}$ & 0.51 \\
\hline Flavor & $5.15^{\mathrm{a}}$ & $5.01^{a}$ & $4.82^{\mathrm{a}, \mathrm{b}}$ & $2.99^{d}$ & $3.62^{c, d}$ & $4.62^{a, b}$ & $4.31^{\mathrm{b}, \mathrm{c}}$ & 0.69 \\
\hline Texture & $5.67^{a}$ & $5.25^{a, b}$ & $5.39^{a, b}$ & $4.99^{b}$ & $5.23^{a, b}$ & $5.49^{a, b}$ & $5.32^{a, b}$ & 0.51 \\
\hline Overall impression & $5.29^{a}$ & $5.07^{a, b}$ & $5.11^{a, b}$ & $3.75^{c}$ & $4.05^{\mathrm{c}}$ & $4.79^{a, b}$ & $4.67^{\mathrm{b}}$ & 0.55 \\
\hline
\end{tabular}

Means in a row followed by different letters are significantly different $(p \leq 0.05)$, with ${ }^{\text {a }}$ representing the higher value.

*Minimum significant difference obtained from the Tukey's test. 


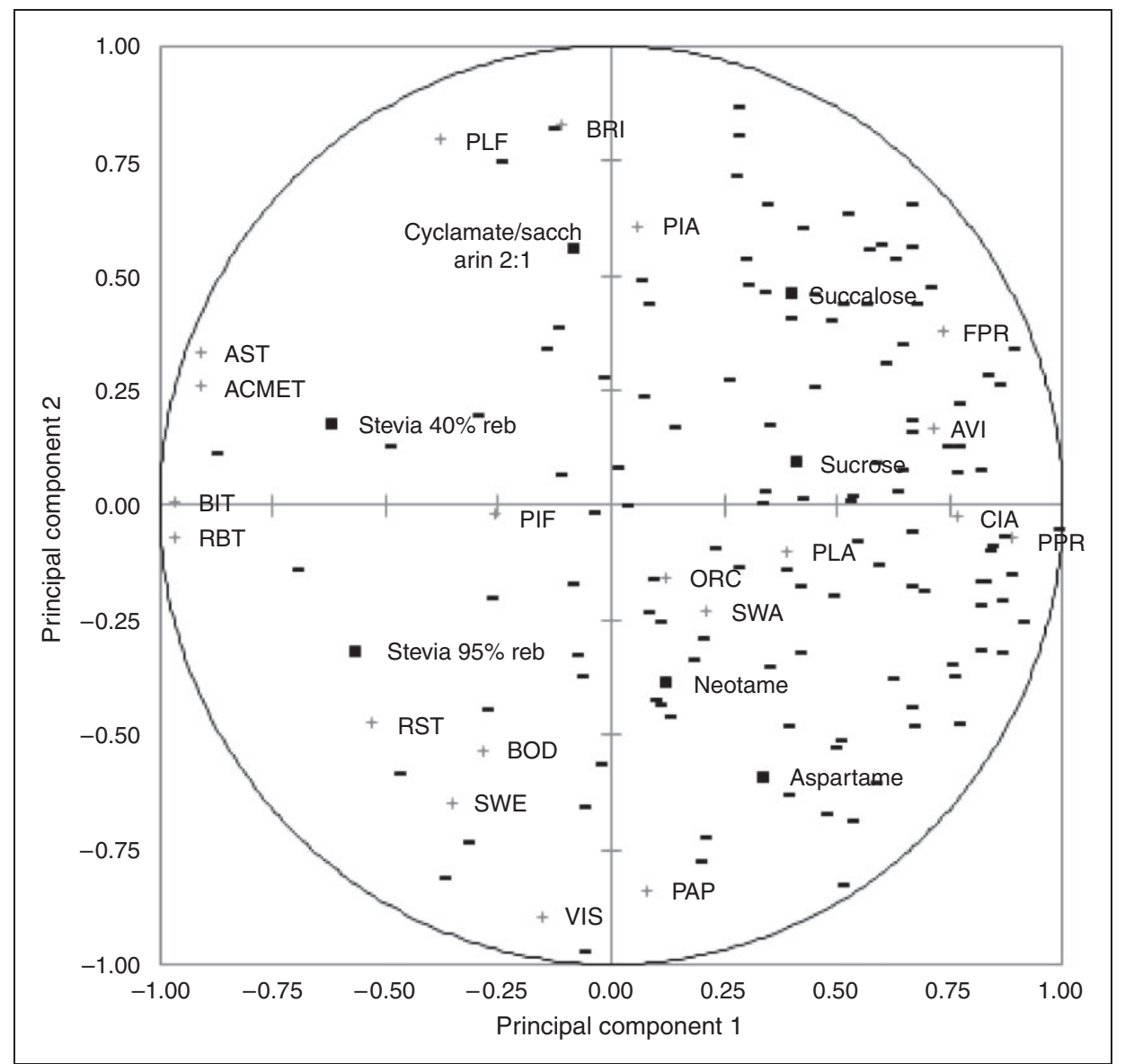

Figure 2. External preference mapping indicating attributes, positions of consumers, and samples of pitanga nectar prepared with different sweeteners (PC1 x PC2 45.82\%).

ORC: orange color; FPR: foam presence; PPR: particle presence; AVI: apparent viscosity; BRI: brightness; PIA: pitanga odor; SWA: sweet odor; PLA: pitanga leaf odor; CIA: citrus odor; PIF: pitanga flavor; SWE: sweetness; BIT: bitterness; RST: residual sweet taste; RBT: residual bitter taste; AST: astringency; ACI: acidity; PLF: pitanga leaf flavor; MET: metallic flavor; VIS: viscosity; BOD: body; PAP: particle presence.

the descriptors' sweet aftertaste and bitter aftertaste negatively influenced the acceptance after 120 days of storage time (Cadena et al., 2013).

Attributes such as bitterness and residual flavors are undesirable in fruit nectar, because they can reduce the perception of fruit flavor, mischaracterizing the product (Brito and Bolini, 2009). One way to reduce these undesirable effects would be by using sweeteners which are responsible for high values of these attributes in synergy with other sweeteners. One example is the already known synergic effects in the use of cyclamate/ saccharin blend, which decreases the residual bitter taste and the metallic flavor of saccharin (Hough, 1996; Salminen and Hallikainen, 2002). This effect might be tested with stevia and other sweeteners in order to observe the resultant profile. For acerola nectar, a solution to reduce the bitterness and to increase the acceptability of samples sweetened with stevia extracts was the use of extracts with rebaudioside higher levels, according to Dutra and Bolini (2013). The authors reported that acerola nectar samples sweetened with stevia containing higher levels of rebaudioside were more accepted than the sample sweetened with stevia extract with $40 \%$ rebaudioside. For pitanga nectar this difference was not significant; however, a tendency could be observed, highlighting the necessity to study the sweeteners in different products.

\section{CONCLUSIONS}

The pitanga nectar samples prepared with sucralose, aspartame, and the 2:1 cyclamate/saccharin blend had sensory profiles similar to that of the sample prepared with sucrose. The attributes that further differentiated the samples were: sweetness, residual sweet taste, bitterness, and residual bitter taste. The sample prepared with neotame stood out for the attributes of sweetness and residual sweet taste, and samples prepared with stevias stood out for the attributes of bitterness and residual bitter taste. 


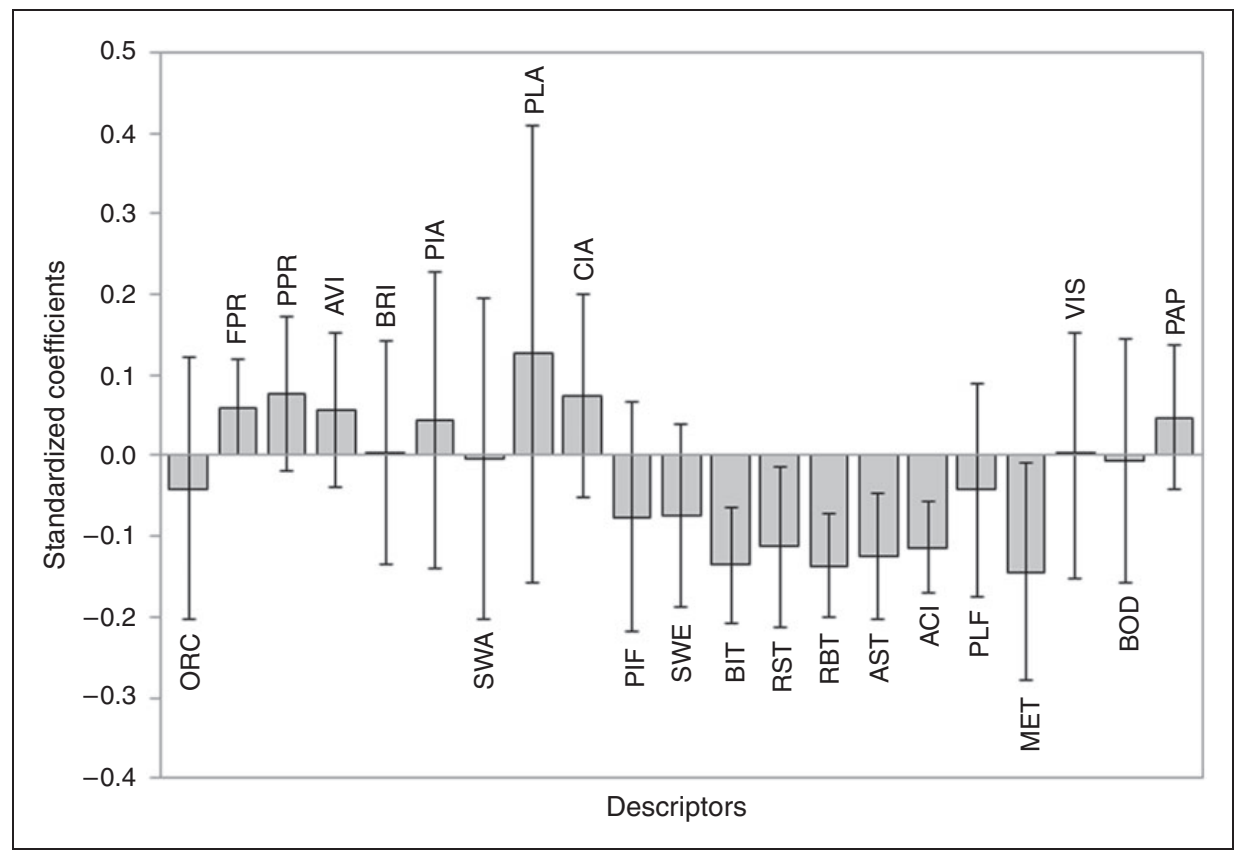

Figure 3. Standardized coefficients from the regression analysis by partial least squares between the descriptors and the overall impression means for the pitanga nectar samples prepared with different sweeteners.

ORC: orange color; FPR: foam presence; PPR: particle presence; AVI: apparent viscosity; BRI: brightness; PIA: pitanga odor; SWA: sweet odor; PLA: pitanga leaf odor; CIA: citrus odor; PIF: pitanga flavor; SWE: sweetness; BIT: bitterness; RST: residual sweet taste; RBT: residual bitter taste; AST: astringency; ACI: acidity; PLF: pitanga leaf flavor; MET: metallic flavor; VIS: viscosity; BOD: body; PAP: particle presence.

Consumers' most accepted samples were prepared with sucrose, sucralose, aspartame, and neotame. The descriptor terms which showed negative influence on the acceptance test were: residual sweet taste, bitterness, residual bitter taste, astringency, acidity, and metallic flavor.

\section{ACKNOWLEDGMENTS}

The authors acknowledge the generous cooperation of the participating tasters and assessors.

\section{DECLARATION OF CONFLICTING INTERESTS}

The author(s) declared no potential conflicts of interest with respect to the research, authorship, and/or publication of this article.

\section{FUNDING}

The author(s) disclosed receipt of the following financial support for the research, authorship, and/or publication of this article: the Conselho Nacional de Desenvolvimento Científico e Tecnológico- $\mathrm{CNPq}-$ Brazil.

\section{REFERENCES}

Amerine MA, Pangborn RM and Roessler EB. (1965). Principles of Sensory Evaluation of Food. New York, NY: Academic Press, pp. 321-348.
Augusto MMM, Queiroz MI and Viotto WH. (2005). Selection and screening of a descriptive panel for evaluation of bitter taste in Brazilian prato cheese. Ciencia $e$ Tecnologia de Alimentos 27(4): 849-852.

Barriocanal L, Palacios M, Benitez G, Benitez S, Jimenez J and Jimenez N. (2008). Apparent lack of pharmacological effect of steviol glycosides used as sweeteners in humans, a pilot study of repeated exposures in some normatensive and hypotensive individuals and in type 1 and type 2 diabetics. Regulatory Toxicology and Pharmacology 51(1): 37-41.

Basu S, Shivhare US and Singh TV. (2013). Effect of substitution of stevioside and sucralose on rheological, spectral, color and microstructural characteristics of mango jam. Journal of Food Engineering 114(1): 465-476.

Brito CAK and Bolini HMA. (2009). Perfil sensorial de edulcorantes em néctar de goiaba. Alimentos e Nutrição 20(4): 561-572.

Cadena RS, Cruz AG, Rolim Netto R, Castro WF, Faria JAF and Bolini HMA. (2013). Sensory profile and physicochemical characteristics of mango nectar sweetened with high intensity sweeteners throughout storage time. Food Research International 54(2): 1670-1679.

Cardoso JMP and Bolini HMA. (2008). Descriptive profile of peach nectar sweetened with sucrose and different sweeteners. Journal of Sensory Studies 23(6): 804-816.

Carrol JD. (1972). Individual differences and multidimensional scaling. In: Shepard RN, Romney AK and Nerlove SB (eds) Multidimensional Scaling: Theory and 
Applications in the Behavioural Sciences. New York, NY: Academic Press, pp. 105-155.

Damásio MH and Costell E. (1991). Análisis sensorial descriptivo: Generación de descriptores y selección de catadores. Revista Agroquímica y Tecnologia de Alimentos 3(2): 165-178.

Dutra MBL and Bolini HMA. (2013). Sensory and physicochemical evaluation of acerola nectar sweetened with sucrose and different sweeteners. Food Science and Technology 33(4): 612-618.

Elortondo ZJP, Ojeda M, Albisu M, Salmerón J, Etayo I and Molina M. (2007). Food quality certification: An approach for the development of accredited sensory evaluation methods. Food Quality and Preference 18(2): 425-439.

Flamm WG, Blackburn GL, Comer CP, Mayhew DA and Stargel WW. (2003). Long-term food consumption and body weight changes in neotame safety studies are consistent with the allometric relationship observed for other sweeteners and during dietary restrictions. Regulatory Toxicology and Pharmacology 38(1): 144-156.

Freitas MLF, Dutra MBL and Bolini HMA. (2014). Development of pitanga nectar with different sweeteners by sensory analysis: Ideal pulp dilution, ideal sweetness, and sweetness equivalence. Food Science and Technology 34(1): 174-180.

Garmus TT, Paviani LC, Queiroga CL, Magalhães PM and Cabral FA. (2014). Extraction of phenolic compounds from pitanga (Eugenia uniflora L.) leaves by sequential extraction in fixed bed extractor using supercritical $\mathrm{CO}_{2}$, ethanol and water as solvents. The Journal of Supercritical Fluids 86(1): 4-14.

Ghanta S, Banerjee A, Poddar A and Chattopadhyay S. (2007). Oxidative DNA damage preventive activity and antioxidant potential of Stevia rebaudiana (Bertoni) Bertoni, a natural sweetener. Journal of Agricultural Food Chemistry 55(1): 10962-10967.

Greenhoff K and Macfie HJH. (1994). Preference mapping in practice. In: Macfie $\mathrm{HJH}$ and Thompson DMH (eds) Measurement of Food Preferences. London: Blackie Academic and Professional, pp. 137-166.

Higginbotham JD. (1983). Recent developments in nonnutritive sweeteners. In: Gremby TH, Parker KJ and Lindley MG (eds) Developments in Sweeteners-2. London: Applied Science Publ., pp. 119-155.

Hough L. (1996). High-intensity, low-calorie sweeteners. In: Khan R (ed.) Low-Calorie Foods and Food Ingredients. Glasgow: Blackie Academic \& Professional, pp. 138-162.

Hough G, Wakeling I, Mucci A, Chambers E, Gallardo IM and Alves LR. (2006). Number of consumers necessary for sensory acceptability tests. Food Quality and Preference 17(6): 522-526.

Karwowski MSM, Masson ML, Lenzi MK, Scheer AP and Haminiuk CWI. (2013). Characterization of tropical fruits: Rheology, stability and phenolic compounds. Acta Alimentaria 42(4): 586-598.

Macfie HJH. (1989). Assessment of the sensory properties of food. Journal of Sensory Studies 4(1): 129-148.
Mahar A and Duizer LM. (2007). The effect of frequency of consumption of artificial sweeteners on sweetness liking by women. Journal of Food Science 72(9): 714-718.

Meilgaard M, Civille GV and Carr BT. (2007). Sensory Evaluation Techniques, 4th edn. New York, NY: CRC Press, pp. 173-186.

Moraes PCBT and Bolini HMA. (2010). Different sweeteners in beverages prepared with instant and roasted ground coffee: Ideal and equivalent sweetness. Journal of Sensory Studies 25(1): 215-225.

Moskowitz HR. (1988). Applied Sensory Analysis of Foods. Boca Raton, FL: CRC Press, pp. 43-73.

Nabors LO. (2002). Sweet choices: Sugar replacements for foods and beverages. Food Technology 56(7): 28-35.

Newsome R. (1993). Sugar substitutes. In: Altschul AM (ed.) Low Calorie Foods Handbook. New York, NY: Marcel Dekker, pp. 139-170.

Ranney RE, Opperman JA, Muldoon E and McMahon FG. (1976). Comparative metabolism of aspartame in experimental animals and humans. Journal of Toxicology and Environmental Health 2(2): 441-451.

Resano H, Sanjuán AI, Cilla I, Roncalés P and Albisu LM. (2010). Sensory attributes that drive consumer acceptability of dry-cured ham and convergence with trained sensory data. Meat Science 84(3): 344-351.

Salminen S and Hallikainen A. (2002). Sweeteners. In: Branen AL, Davidson PM, Salminen S and Thorngate JH (eds) Food Additives. New York, NY: Marcel Dekker, pp. 451-456.

Sedivá A, Panovská Z and Pokorny J. (2006). Sensory profiles of sweeteners in aqueous solutions. Czech Journal of Food Science 24(1): 283-287.

Silva SM. (2006). Pitanga. Revista Brasileira de Fruticultura 28(1): 1-159.

Soares LMV, Shishido K, Moraes AMM and Moreira VA. (2004). Mineral composition of brazilian concentrate fruit juices. Ciência e Tecnologia de Alimentos 24(2): 202-206.

Stone H, Bleibaum RN and Thomas HA. (2012). Sensory Evaluation Practices. New York, NY: Academic Press, pp. 291-300.

Tenenhaus M, Pagès J, Ambroisine L and Guinot C. (2005). PLS methodology to study relationships between hedonic judgments and products characteristics. Food Quality and Preference 16(1): 315-325.

Umbelino DC and Bolini HMA. (2005). Sensory profile of mango juice sweetened with different sweeteners and sucrose. Alimentos e Nutrição 16(4): 327-336.

Viberg H and Fredriksson A. (2011). Neonatal exposure to sucralose does not alter biochemical markers of neuronal development or adult behavior 27(1): 81-85.

Voorpostel CR, Dutra MBL and Bolini HMA. (2014). Sensory profile and drivers of liking for grape nectar among smoker and nonsmoker consumers. Food Science and Technology 34(1): 164-173.

Wells AG. (1989). The use of intense sweeteners in soft drinks. In: Gremby TH (ed.) Progress in Sweeteners. New York, NY: Elsevier Applied Science, pp. 169-214. 